This put me in mind of a long serving medical records officer who commented on the clinical descriptions accompanying medical recommendations. His years of experience had led him to observe that for many general practitioners the accompanying description bore a remarkable similarity to that of the psychiatrist and, in fact, was often of the same wording. It is clear that many GP's do not feel sufficiently confident to form an independent assessment, nor to challenge the opinion arrived at. This is contrary to the spirit of the mental health legislation and deprives the patient of an autonomous assessment by a second doctor.

This situation is unlikely to be rectified unless the GPs providing theses assessments have obtained sufficient training and experience, so enabling them to fulfil the role envisaged by the legislation. The average GP is involved very infrequently and perhaps it would be more appropriate to have a panel of suitably, qualified GPs for this purpose. Where the individual patient's GP is not on this panel then an approved doctor could provide the recommendation.

Guy's Hospital

HARRY DOYLE

London SE1 9RT

\section{Recruitment of patients with panic disorder}

DeAR Sirs

We read with interest Dr Dratcu's article on the recruitment of patients with panic disorder through a magazine article on the subject (Psychiatric Bulletin, July 1993, 17, 416-417). This is similar to our experience at the Royal London Hospital in recruiting subjects with panic disorder.

Initially requests were made for patients with panic disorder to psychiatric colleagues, CPNs and local GPs. The response was poor with just three patients referred, not all of whom were suitable. This led us to place a small $10 \times 7 \mathrm{~cm}$ notice of our interest in subjects with panic disorder in a local paper. Over 60 telephone enquiries were received and a detailed questionnaire sent to respondents. Thirty-eight returned the questionnaire (11 male and 27 female), the majority of whom described clear panic attacks. Only 11 patients reported current contact with their GP (and as such available to be referred from this source). Fourteen patients reported no contact at all with their GP or hospital for panic disorder although most met the trial criteria.

We were concerned we might recruit subjects (with generalised anxiety disorder) addicted to benzodiazepines. Surprisingly this was not the case, with only eight reporting current benzodiazepine use. A further ten were receiving antidepressants, beta blockers or neuroleptics (3) and 18 were receiving no medication.
A notice of interest in panic disorder placed in a local paper therefore results in a good response with many cases being recruited who have not previously presented to medical services.

RichaRd DUFFETT J. COOKSON Royal London Hospital Trust Department of Human Psychopharmacology

London E3 4LL

\section{Psychiatry and the media}

\section{DeAr SirS}

I am writing to reiterate the concern of many psychiatrists (including that of Clark, Psychiatric Bulletin, July 1993, 17, 440) who are appalled by misinformation being conveyed by the media to unsuspecting laymen about psychiatric ailments and their treatment.

On 5 May 1993 BBC ('The Family Game', QED) introduced a child as a 'problem child' on the national network. It is of great concern to those who respect the individuality and confidentiality of children in these matters that such a presentation should be made. It is difficult to comprehend the ethics of presenting an innocent child who surely did not understand the nature and purpose of this recording, nor had the ability to give consent. A few generations of psychiatrists have expressed concern about the stigma and labelling that psychiatric ailments attract. I dread the day when the child presented on the national TV network grows up and asks "why did you do this to me...?"

My concern increased by the time the programme concluded as there was no evidence in the presentation, historical or from the programme, that the treatment proposed was effective. The actual game seemed to be the interviewers filling in forms, drawing conclusions, making assumptions about things said and unsaid and keeping pressure on their clients until the final aim was achieved; this seemed to be the self-gratification of the therapists when mother entered the game, yielded to all pressures and declared how good they were and how ignorant she was.

There may have been a satisfactory change in the child with therapy. Only the clinician treating the child will know for sure. However, whether it was brought out in the presentation or whether consideration was given to the implications it will have on the future wellbeing of this child, are questions which need to be asked. Our College must contribute to programmes on psychiatric issues to ensure that the programmes imply consensus professional opinion.

University Hospital

Dinesh K. ARya

Nottingham NG7 2UH 